\title{
Integrated Rate Equation Considering Product Inhibition and Its Application to Kinetic Assay of Serum Ethanol
}

\author{
Fei LiaO, ${ }^{* \dagger}$ Li-na ZhaO, ${ }^{*}$ Yun-sheng ZhaO,* Jia TAO,* and Yuping ZuO** \\ *Laboratory of Bioinformatics \& Molecular Engineering, Chongqing Key Laboratory of Biochemistry \& \\ Molecular Pharmacology, College of Pharmaceutical Sciences, Chongqing Medical University, \\ Chongqing 400016, People's Republic of China \\ **Department of Biochemistry \& Molecular Biology, College of Basic Medical Sciences, \\ Chongqing Medical University, Chongqing 400016, People's Republic of China
}

\begin{abstract}
Kinetic assay of serum ethanol was investigated by predicting maximal product absorbance at $340 \mathrm{~nm}\left(A_{\mathrm{mk}}\right)$ through fitting to the yeast alcohol dehydrogenase reaction curve with the integrated rate equation, taking into account product inhibition in the presence of semicarbazide. Predicted $A_{\mathrm{mk}}$ linearly responded to the preset constant of steady-state concentration of acetaldehyde $\left(C_{\text {ald }}\right)$. An exponential correlation function was established between desired $C_{\text {ald }}$ and putative $A_{\mathrm{mk}}$ for authentic ethanol. For unknown samples, iterative fitting to reaction curve till preset constant $C_{\text {ald }}$ and resultant $A_{\mathrm{mk}}$ satisfied this exponential correlation function yielded $A_{\mathrm{mk}}$ with variation coefficient $<4.3 \%$. Variations in enzyme activity, data range and kinetic parameters showed negligible effects. The recovery was consistent to $100 \%$ with resistance to methanol and isopropanol. The upper limit of linear response for $A_{\mathrm{mk}}$ was about 40 times of the lower limit. These results indicated that this kinetic method was reliable for serum ethanol assays with obvious advantages.
\end{abstract}

(Received June 28, 2006; Accepted November 2, 2006; Published April 10, 2007)

\section{Introduction}

Selective oxidation of ethanol to acetaldehyde catalyzed by alcohol dehydrogenase $(\mathrm{ADH})$ in the presence of nicotinamide adenine dinucleotide $\left(\mathrm{NAD}^{+}\right)$is widely used for enzymatic assay of serum ethanol by quantifying the indicator product, reduced nicotinamide adenine dinucleotide (NADH). Among $\mathrm{ADH}$ methods in use, however, the classical kinetic method is sensitive to factors affecting ADH activity while the equilibrium method shows lower efficiency and narrower range of linear response. ${ }^{1,2}$ Recently, a new kinetic strategy was established for enzymatic analysis by predicting, instead of direct assay, the detector signal after the completion of enzyme reaction with an integrated method, i.e. fitting the integrated rate equation to an enzyme reaction curve. . $^{3-8}$ This kinetic strategy shows resistance to most factors affecting enzyme activity and much wider range of linear response. Therefore, this kinetic strategy is anticipated to be useful for serum ethanol assay with ADH action.

However, there are some problems associated with serum ethanol assay by this kinetic method. ADH is inhibited by its products NADH and acetaldehyde. ${ }^{9}$ Preliminary analysis found out that the ignorance of acetaldehyde inhibition on ADH resulted in $\sim 10 \%$ deviation between this kinetic method and the equilibrium method. This kinetic strategy worked for glutathione assay by using the integrated rate equation that took into account product inhibition on glutathione-S-transferase. ${ }^{7,10}$ With the availability of instantaneous acetaldehyde concentration, the integrated rate equation for $\mathrm{ADH}$ reaction taking into account the inhibition from both products can be derived. Thus this kinetic method may still

$\dagger$ To whom correspondence should be addressed.

E-mail: liaofeish@vip.sina.com; liaofeish@yahoo.com be feasible for serum ethanol assay by taking product inhibition on ADH into account. Moreover, this kinetic method requires reaction data of substrate consumption as high as possible for analysis by the integrated rate equation using the predictor variable of reaction time. ${ }^{3-8}$ The reversibility of the ADH reaction makes only data of $<35 \%$ substrate consumption available for analysis. Consequently, an acetaldehyde scavenger such as semicarbazide has to be used to remove acetaldehyde to get reaction data of $>80 \%$ substrate consumption. But this strategy results in a loss of the stoichiometric relationship between NADH and acetaldehyde, and the unavailability of instantaneous acetaldehyde concentration prevents the derivation of the integrated rate equation with the predictor variable of reaction time for $\mathrm{ADH}$ reaction taking product inhibition into account. Theoretically, product inhibition can be incorporated into the integrated rate equation for $\mathrm{ADH}$ reaction by solving a group of differential rate equations including that for acetaldehyde reaction to semicarbazide, provided that both instantaneous concentration of semicarbazide and the secondorder reaction rate constant for its reaction to acetaldehyde are available. The initial concentration of semicarbazide in $\mathrm{ADH}$ reaction solution can be preset at a value $>100$-fold of the maximal ethanol concentration under analysis to approximate the instantaneous semicarbazide concentration as a known constant during $\mathrm{ADH}$ reaction. However, the second-order rate constant for semicarbazide reaction to acetaldehyde is currently unavailable, in addition to the difficulty in deriving the integrated rate equation that uses the predictor variable of reaction time. Therefore, some special method is needed to approximate acetaldehyde inhibition on ADH for ethanol assay by this kinetic method.

The reaction between semicarbazide and acetaldehyde is relatively fast in alkaline solution. If ADH activity is low enough and the initial concentration of semicarbazide is high enough, steady-state of acetaldehyde concentration in reaction solution 
due to consecutive reactions can be easily achieved. Therefore, it may be reasonable to approximate instantaneous acetaldehyde concentration as an unknown constant to treat its inhibition on ADH. Moreover, after the inhibition from both products was taken into account, this approximation gives the integrated rate equation for $\mathrm{ADH}$ reaction that uses the predictor variable of reaction time. Therefore, we used an initial semicarbazide concentration $>100$-fold, and $\mathrm{NAD}^{+}$concentration $>10$-fold, of the maximal ethanol concentration in reaction solution at lower $\mathrm{ADH}$ activity for kinetic analysis of $\mathrm{ADH}$ reaction process. This strategy allowed the approximation of the steady-state acetaldehyde concentration as an unknown constant. Thus, a kinetic ADH method was established for serum ethanol assay by predicting maximal NADH absorbance after the completion of ADH reaction through iterative fitting to ADH reaction curve with the integrated rate equation that took product inhibition into account.

\section{Experimental}

\section{Reagents and chemicals}

Nicotinamide adenine dinucleotide $\left(\mathrm{NAD}^{+}\right.$, Sigma N7004), yeast alcohol dehydrogenase (ADH, Sigma A7011), semicarbazide hydrochloride (Sigma) were used as supplied. Trichloroacetic acid, absolute ethanol, disodium pyrophosphate, methanol and isopropanol were domestic analytical chemicals. Proteins in serum samples from the nearby blood center were precipitated by $5 \%$ trichloroacetic acid before analysis (the centrifuge tube was sealed with Parafilm from Sigma). The standard solution of authentic ethanol was made in aqueous solution of $5 \%$ trichloroacetic acid.

\section{Determining maximal product absorbance by the equilibrium method}

The maximal product absorbance was measured by the equilibrium method $\left(A_{\mathrm{me}}\right)$ for authentic ethanol in reaction solution $<0.17 \mathrm{mmol} / \mathrm{L}$ after $50 \mathrm{~min}$ reaction with the system described below, ${ }^{2}$ or it was predicted by extrapolation based on the response of $A_{\text {me }}$ to ethanol in reaction solution $<0.17$ $\mathrm{mmol} / \mathrm{L}$ when the final ethanol concentration was $>0.17$ $\mathrm{mmol} / \mathrm{L}$. Ethanol concentration in stock solution was calibrated by this equilibrium method using the absorptivity of 6.31 $(\mathrm{mmol} / \mathrm{L})^{-1} \mathrm{~cm}^{-1}$ for $\mathrm{NADH}$ at $340 \mathrm{~nm}$.

\section{Monitoring of ADH reaction}

The final reaction mixture contained $1.30 \mathrm{ml}$ disodium pyrophosphate buffer $(0.20 \mathrm{~mol} / \mathrm{L}$ plus $75.0 \mathrm{mmol} / \mathrm{L}$ semicarbazide, $\mathrm{pH}$ 9.2), $80 \mu \mathrm{l} \mathrm{NAD}^{+}$solution (56.0 mmol/L), 20 $\mu \mathrm{l}$ ADH solution $(12.5 \mathrm{mg} / \mathrm{ml}, \sim 3750 \mathrm{U} / \mathrm{ml}$ as stated by the provider) and $100 \mu \mathrm{l}$ protein-free sample. ${ }^{1,2} \mathrm{ADH}$ reaction was initiated by adding ADH solution into the quartz curvet $(10 \mathrm{~mm}$ light path). Unless stated otherwise, the absorbance was monitored at $340 \mathrm{~nm}$ on Shimadzu UV 265 spectrophotometer from $40 \mathrm{~s}$ after reaction initiation until $6 \mathrm{~min}$ at $10 \mathrm{~s}$ interval using the mixture minus $\mathrm{ADH}$ as blank to correct the absorbance of $\mathrm{NAD}^{+}$. The highest absorbance was $<1.270$.

\section{Approximating the desired steady-state concentration of acetaldehyde}

Based on the method described below, maximal NADH absorbance after the completion of $\mathrm{ADH}$ reaction $\left(A_{\mathrm{mk}}\right)$ was predicted with steady-state concentration of acetaldehyde in reaction solution $\left(C_{\text {ald }}\right)$ preset as a constant. Data from $40 \mathrm{~s}$ after reaction initiation until $6 \mathrm{~min}$ reaction were analyzed unless stated otherwise. The desired $C_{\text {ald }}$ was that to give $A_{\mathrm{mk}}$ with deviation $<0.0015$ from $A_{\text {me }}$, determined by the equilibrium

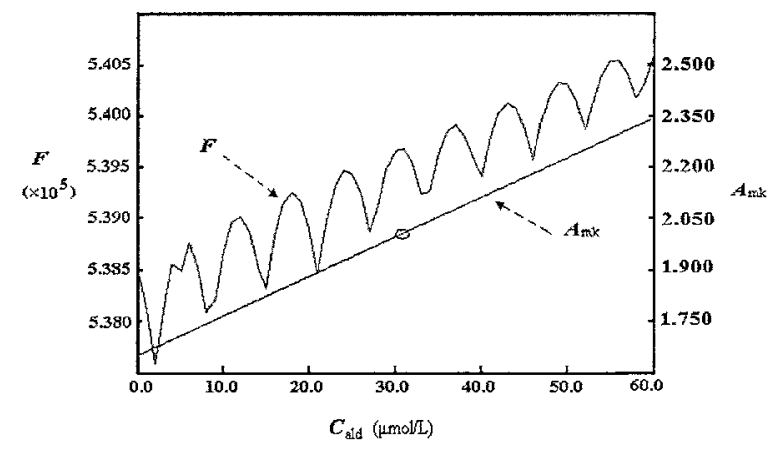

Fig. 1 The responses of $F$ value and $A_{\mathrm{mk}}$ to the preset constant of $C_{\text {ald }}$ for $0.31 \mathrm{mmol} / \mathrm{L}$ ethanol in reaction solution by fitting the integrated rate equation to the reaction curve. The open circle indicated $A_{\mathrm{mk}}$ consistent with the equilibrium method.

method directly or indirectly when ethanol in reaction solution was $>0.17 \mathrm{mmol} / \mathrm{L}$. The correlation of desired $C_{\text {ald }}$ to $A_{\text {me }}$ was modeled by an exponential additive function of $A_{\text {me }}$ using the cftool module in Matlab 6.5 (Fig. 1). This correlation function was used to approximate the desired constant of $C_{\text {ald }}$ during iterative fitting to predict $A_{\text {mk }}$.

\section{Predicting maximal product absorbance by iterative fitting to} ADH reaction curve

The inhibition of acetaldehyde and NADH on $\mathrm{ADH}$ was included in the integrated rate equation for $\mathrm{ADH}$ reaction that was a linear function of reaction time (see Appendix). ${ }^{9}$ The apparent equilibrium constant was adjusted to the final $\mathrm{pH}$ of the reaction solution (about 8.8). Unless stated otherwise, ADH $K_{\mathrm{m}}$ for ethanol was fixed at $7.6 \mathrm{mmol} / \mathrm{L}$ (by Lineweaver-Burk plot analysis) and other parameters were from literacy. ${ }^{9}$ By presetting $C_{\text {ald }}$ as a constant and using $F$ value to judge the goodness of fit, $A_{\mathrm{mk}}$ was estimated as a nonlinear parameter by stepwise adjustment at the step of $0.001 .^{3-8}$ For iterative fitting, $C_{\text {ald }}$ in the first run was fixed at the value calculated with the exponential correlation function using maximal experimental absorbance as the predictor variable. Thereafter, $A_{\mathrm{mk}}$ was predicted iteratively with current $C_{\text {ald }}$ approximated according to the correlation function using previous $A_{\mathrm{mk}}$ as the predictor variable and final $A_{\mathrm{mk}}$ was that met the convergence critique, i.e. absorbance difference $<0.0015$ unless stated otherwise, during iteration. Ethanol concentration in reaction solution was calculated from $A_{\mathrm{mk}}$ using the preset absorptivity for NADH.

\section{Programming and statistic analysis}

The program for fitting the integrated rate equation to $\mathrm{ADH}$ reaction curve was written in Visual Basic 6.0, and data were recorded in a text file to be read-in by the program. $A_{\mathrm{mk}}$ for best fitting based on the global maximal $F$ value was the desired parameter with respect to stepwise adjustment of $A_{\mathrm{mk}}$ from that 0.001 above the highest experimental absorbance until $2.300 .^{3-8}$ The lower limit of linear response was thrice the standard error of estimate, and the upper limit was that with deviation from the linear plot below thrice the standard error of estimate.

\section{Results}

\section{The prediction of $A_{m k}$ by the integrated method}

By analyzing data monitored within 6 min reaction in the presence of semicarbazide, it was found that the ignorance of 


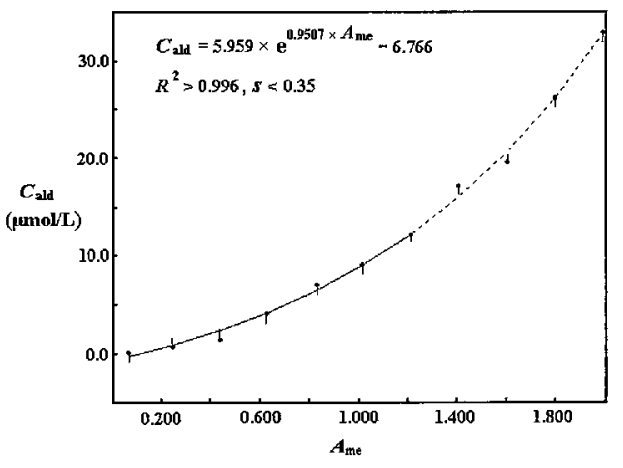

Fig. 2 Correlation of the desired steady-state concentration of acetaldehyde $\left(C_{\text {ald }}, \mu \mathrm{mol} / \mathrm{L}\right)$ to putative maximum product absorbance by the equilibrium method $\left(A_{\mathrm{me}}\right)$. Data with dashed line were for $A_{\mathrm{me}}$ $>1.200$ estimated by extrapolation based on the linear response for ethanol $<0.17 \mathrm{mmol} / \mathrm{L}$. Vertical bar indicated variation in desired $C_{\text {ald }}$ by assays in triplicate.

the inhibition of residual acetaldehyde on $\mathrm{ADH}$ gave $A_{\mathrm{mk}}$ with $\sim 6 \%$ negative deviation from that obtained by the equilibrium method for ethanol $<0.17 \mathrm{mmol} / \mathrm{L}$ in reaction solution. The deviation was increased to $>20 \%$ for $0.31 \mathrm{mmol} / \mathrm{L}$ ethanol in reaction solution. However, the deviation was $<2 \%$ when data of more than $90 \%$ oxidation of ethanol $<0.17 \mathrm{mmol} / \mathrm{L}$ were analyzed, but more than 30 min reaction was required to obtain these data. With higher concentration of ethanol and less percentage of substrate consumption for analysis, $A_{\mathrm{mk}}$ showed higher sensitivity to the inhibition of residual acetaldehyde.

There was always better fitting to $\mathrm{ADH}$ reaction curve with the integrated rate equation when acetaldehyde inhibition on $\mathrm{ADH}$ was taken into account. There were linear responses of predicted $A_{\mathrm{mk}}$ to the preset constant of $C_{\text {ald }}$ for all tested reaction curves and the slopes for these responses were comparable to the preset absorptivity for NADH (Fig. 1). Referring to $A_{\text {me }}$ by the equilibrium method, there was reliable $A_{\mathrm{mk}}$ for ethanol in reaction solution when $C_{\text {ald }}$ was optimized. For the prediction of $A_{\mathrm{mk}}$ for $0.31 \mathrm{mmol} / \mathrm{L}$ ethanol in reaction solution with absorbance deviation $<0.0015$ from $A_{\text {me }}$, the desired $C_{\text {ald }}$ was $<0.045 \mathrm{mmol} / \mathrm{L}$. However, by fitting to ADH reaction curve with the integrated rate equation that took product inhibition into account, there was a zigzagging increase of $F$ value showing many regional maximums in response to stepwise increases of $C_{\text {ald }}$ till $0.060 \mathrm{mmol} / \mathrm{L}$.

ADH $K_{\mathrm{m}}$ for ethanol showed small effects on the prediction of $A_{\mathrm{mk}}$. At $3.0 \mathrm{mmol} / \mathrm{L} \mathrm{NAD}^{+}, \mathrm{ADH} K_{\mathrm{m}}$ for ethanol was $7.6 \pm 0.8$ $\mathrm{mmol} / \mathrm{L}(n=3)$ while it was $17 \mathrm{mmol} / \mathrm{L}$ at $1.0 \mathrm{mmol} / \mathrm{L} \mathrm{NAD}^{+}{ }^{9}$ Fixing $K_{\mathrm{m}}$ as a constant at $17 \mathrm{mmol} / \mathrm{L}$ led to higher $C_{\text {ald }}$ desired for reliable $A_{\mathrm{mk}}$ when the same data were analyzed. When $C_{\text {ald }}$ was fixed, the increase of ADH $K_{\mathrm{m}}$ for ethanol from 7.6 to 17.0 $\mathrm{mmol} / \mathrm{L}$ led to $<3 \%$ decrease of predicted $A_{\mathrm{mk}}$. However, with the same $C_{\text {ald }}$ fixed as a constant, presetting $K_{\mathrm{m}}$ of $\mathrm{ADH}$ for ethanol as a constant at $7.6 \mathrm{mmol} / \mathrm{L}$ conferred on this kinetic method higher resistance to variation in data range for analysis. The variations in other parameters except the equilibrium constant also showed negligible effects on $A_{\mathrm{mk}}$, and the adjustment of the equilibrium constant to meet the experimental $\mathrm{pH}$ enhanced the resistance of $A_{\mathrm{mk}}$ prediction to the variation of data range.

The correlation of desired $C_{\text {ald }}$ to putative maximal product absorbance

Referring to the equilibrium method, it was found that the desired $C_{\text {ald }}$ to give reliable $A_{\mathrm{mk}}$ for known concentrations of
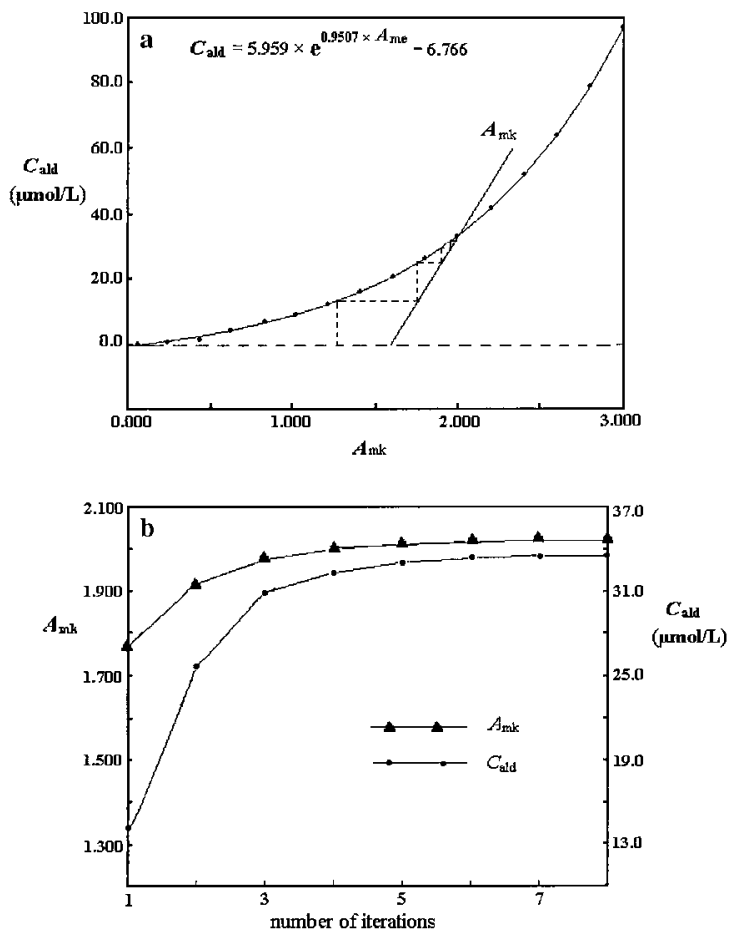

Fig. 3 The prediction of $A_{\mathrm{mk}}$ for $0.31 \mathrm{mmol} / \mathrm{L}$ ethanol in reaction solution by iterative fitting to ADH reaction curve. (a) The principle for iterative fitting to $\mathrm{ADH}$ reaction curve to predict $A_{\mathrm{mk}}$. (b) The converging process of iterative fitting to predict $A_{\text {mk }}$.

ethanol in reaction solution nonlinearly correlated to $A_{\mathrm{me}}<1.100$ (Fig. 2). All tested models to describe these data for $A_{\mathrm{me}}<1.100$ failed to predict the $C_{\text {ald }}$ desired for predicting $A_{\mathrm{mk}}$ at $0.31 \mathrm{mmol} / \mathrm{L}$ ethanol in reaction solution. Referring to $A_{\text {me }}$ by extrapolation, it was found that the desired $C_{\text {ald }}$ for reliable prediction of $A_{\mathrm{mk}}$ was available even at $0.31 \mathrm{mmol} / \mathrm{L}$ ethanol, and these desired $C_{\text {ald }}$ correlated to $A_{\text {me }}$ in an exponential additive pattern (Fig. 2). This exponential correlation function predicted the desired $C_{\text {ald }}$ for known concentrations of ethanol in reaction solution. With $C_{\text {ald }}$ approximated by this exponential correlation function using $A_{\mathrm{me}}$ as the predictor variable, $A_{\mathrm{mk}}$ was predicted with averaged absorbance deviation $<0.001$ for ethanol from 0.031 to 0.31 $\mathrm{mmol} / \mathrm{L}$ in reaction solution. The variation in kinetic parameters for $\mathrm{ADH}$ reaction gave different $C_{\text {ald }}$ for the same $A_{\text {me }}$. However, with these kinetic parameters fixed as constants, there was still exponential response of desired $C_{\text {ald }}$ to $A_{\text {me }}$.

The characterization of this kinetic ADH method by iterative fitting to predict $A_{m k}$

There was a unique intersecting point between the response function of the predicted $A_{\mathrm{mk}}$ to the preset constant of $C_{\text {ald }}$ $<0.060 \mathrm{mmol} / \mathrm{L}$ and the correlation function between desired $C_{\text {ald }}$ and reliable $A_{\mathrm{mk}}$ referring to $A_{\mathrm{me}}$ (Fig. 3a). By iterative fitting to the reaction curve of unknown ethanol in reaction solution with $C_{\text {ald }}$ approximated by this exponential correlation function, i.e. using previous $A_{\mathrm{mk}}$ as the predictor variable to calculate $C_{\text {ald }}$ desired for current fitting based on the exponential correlation function, there was a quick convergence of the fitting to desired $C_{\text {ald }}$ and $A_{\mathrm{mk}}$, the intersecting point of two functions, when the critique was set at absorbance change $<0.0015$ (Fig. 3b). Usually there was less than ten iterations till convergence for ethanol $<0.32 \mathrm{mmol} / \mathrm{L}$ in reaction solution. Using the convergence criteria of absorbance change $<0.0075$, the number of iterations showed only small variation. 
Table 1 Comparison of serum ethanol assay obtained by this kinetic $\mathrm{ADH}$ method $\left(A_{\mathrm{mk}}\right)$ to that obtained by the equilibrium method $\left(A_{\text {me }}\right)$

\begin{tabular}{lcc}
\hline \multicolumn{1}{c}{ Condition } & $A_{\mathrm{mk}}$ & $A_{\mathrm{me}}$ \\
\hline Intra-run precision & & \\
$0.070 \mathrm{mmol} / \mathrm{L}$ & $0.436 \pm 0.004(5)$ & $0.441 \pm 0.005(5)$ \\
$0.150 \mathrm{mmol} / \mathrm{L}$ & $0.950 \pm 0.007(5)$ & $0.954 \pm 0.007(5)$ \\
$0.310 \mathrm{mmol} / \mathrm{L}$ & $1.994 \pm 0.016(5)$ & $\mathrm{ND}$ \\
Inter-run precision & & \\
$0.070 \mathrm{mmol} / \mathrm{L}$ & $0.438 \pm 0.018(4)$ & $0.435 \pm 0.014(4)$ \\
$0.150 \mathrm{mmol} / \mathrm{L}$ & $0.942 \pm 0.021(4)$ & $0.948 \pm 0.016(4)$ \\
Recovery & & \\
$0.070 \mathrm{mmol} / \mathrm{L}$ & $100.8 \pm 2.6 \%(4)$ & $99.0 \pm 2.6 \%(4)$ \\
$0.150 \mathrm{mmol} / \mathrm{L}$ & & \\
Interferences at $0.15 \mathrm{mmol} / \mathrm{L}$ & & \\
ethanol & & \\
Methanol, 45.0 $\mu \mathrm{mol} / \mathrm{L}$ & $0.947 \pm 0.006(3)$ & $0.951 \pm 0.005(3)$ \\
Isopropanol, $90.0 \mu \mathrm{mol} / \mathrm{L}$ & $0.954 \pm 0.007(3)$ & $0.948 \pm 0.007(3)$ \\
ADH at $25 \mathrm{U} / \mathrm{ml}$ & & \\
$0.070 \mathrm{mmol} / \mathrm{L}$ & $0.428 \pm 0.008(4)$ & $0.432 \pm 0.005(4)$ \\
$0.150 \mathrm{mmol} / \mathrm{L}$ & $0.928 \pm 0.004(4)$ & $0.940 \pm 0.004(4)$
\end{tabular}

Number in parentheses was that for independent repeats. $\mathrm{ADH}$ at 50 $\mathrm{U} / \mathrm{ml}$ in reaction solution was used unless stated otherwise. Inter-run precision was determined by independent preparations of sample and duplicated assays each time. The indicated concentration of ethanol was the approximated value in reaction solution. Recovery was determined against ethanol in protein-free supernatant of serum. ND: not determined.

By using the exponential correlation function to approximate $C_{\text {ald }}$ for iterative prediction of $A_{\mathrm{mk}}$ with data monitored within 6 min reaction, it was found that the variation of the starting datum from $40 \mathrm{~s}$ to $2.0 \mathrm{~min}$ after reaction initiation for analysis usually yielded $A_{\mathrm{mk}}$ with a deviation $<1.8 \%$ for ethanol from 0.070 to $0.31 \mathrm{mmol} / \mathrm{L}$ in reaction solution. With data monitored $40 \mathrm{~s}$ after reaction initiation, the variation of the last datum for analysis, from $5.0 \mathrm{~min}$ reaction to $7.0 \mathrm{~min}$ reaction, still gave $A_{\mathrm{mk}}$ with deviation $<2.0 \%$ for these reaction curves. This kinetic ADH method showed recovery consistent to $100 \%$ (Table 1). Its imprecision was $<4.3 \%$ for both intra-run and inter-run repeated assays. It showed resistance to methanol and isopropanol. For ethanol $<0.17 \mathrm{mmol} / \mathrm{L}$ in reaction solution, the reduction of $\mathrm{ADH}$ activity by $50 \%$ caused negative deviation $<3.0 \%$ to both $A_{\mathrm{mk}}$ and $A_{\mathrm{me}}$ while the reduction of ADH activity by $10 \%$ showed no significant effects on $A_{\text {mk }}$ and $A_{\text {me }}$.

The upper limit of linear response of $A_{\mathrm{me}}$ to ethanol concentration in reaction solution $\left(C_{\text {alc }}, \mathrm{mmol} / \mathrm{L}\right)$ was $<0.17$ $\mathrm{mmol} / \mathrm{L}\left(A_{\mathrm{me}}=0.051+6.31 \times C_{\text {alc }}, r>0.9992, s<0.005\right) . \quad A_{\mathrm{mk}}$ predicted by this kinetic method linearly responded to $C_{\text {alc }}$ as high as $0.31 \mathrm{mmol} / \mathrm{L}$ (Fig. $4, A_{\mathrm{mk}}=0.050+6.31 \times C_{\text {alc }}, r>$ $0.9998, s<0.013)$. This upper limit corresponded to a product absorbance about 1.6 times of the preset maximum absorbance measurable by the spectrophotometer. Neither the slope nor the intercept of linear response exhibited differences from the values obtained by the equilibrium method. Moreover, the slope of the response was consistent with the preset absorptivity for NADH. There was a higher standard error of estimate, however, by this kinetic method, which gave the lower limit of $0.10 \mathrm{mmol} / \mathrm{L}$ for serum ethanol. The intercept, by both methods, was due to ethanol contaminated in commercial $\mathrm{NAD}^{+}$ (Sigma N7004 contained the lowest residual ethanol among commercial $\mathrm{NAD}^{+}$tested). This intercept yielded the lower limit of $0.015 \mathrm{mmol} / \mathrm{L}$ ethanol in reaction solution and the upper limit of $4.55 \mathrm{mmol} / \mathrm{L}$ for serum ethanol.

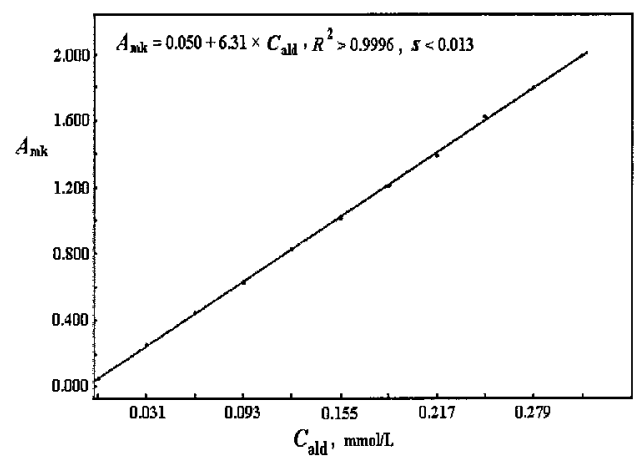

Fig. 4 Response of $A_{\mathrm{mk}}$ by this kinetic ADH method to ethanol concentration in reaction solution $\left(C_{\text {alc }}, \mathrm{mmol} / \mathrm{L}\right)$. All assays were in triplicate with variation coefficient $<2.5 \%$.

\section{Discussion}

Serum ethanol assay by this new kinetic method has potential advantages. However, to meet the prerequisites of this kinetic method, semicarbazide is used to drive the formation of NADH by scavenging acetaldehyde, which inevitably results in difficulty to treat acetaldehyde inhibition on ADH. Theoretical treatment of acetaldehyde inhibition on ADH taking all relevant reactions into account is not practicable. Therefore, some special method has to be used to approximate acetaldehyde inhibition on $\mathrm{ADH}$ for serum ethanol assay by this new kinetic method.

In reaction solution, semicarbazide $>200$-fold of acetaldehyde formed within $6 \mathrm{~min}$ reaction and the reasonably lower $\mathrm{ADH}$ activity supported steady-state concentration of acetaldehyde after $40 \mathrm{~s}$ lag. Therefore, for this kinetic method, the inhibition of acetaldehyde on ADH may be approximated with steadystate acetaldehyde concentration as an unknown constant. The desired steady-state concentration of acetaldehyde is an approximation of overall apparent concentration of acetaldehyde that would be best for fitting the integrated rate equation to $\mathrm{ADH}$ reaction curve. However, the desired steadystate concentration of acetaldehyde can not be estimated simultaneously as a parameter by fitting the integrated rate equation to $\mathrm{ADH}$ reaction curve, because there was no unique maximal $F$ value for the fitting with respect to preset steadystate concentration of acetaldehyde (Fig. 1). Thus, some alternative method has to be used to approximate the steadystate concentration of acetaldehyde.

By analyzing reaction data of known ethanol concentration in reaction solution, we established an exponential correlation function between the desired steady-state concentration of acetaldehyde and putative maximal product absorbance. This exponential correlation function did not parallel with the response function of predicted $A_{\mathrm{mk}}$ to the preset steady-state acetaldehyde concentration (Fig. 3a). Therefore, there must be a unique intersecting point between these two functions within a reasonable range, which can be estimated by iterative fitting till the preset steady-state concentration of acetaldehyde and resultant $A_{\mathrm{mk}}$ met this exponential correlation function. Moreover, the adjustment of the equilibrium constant of $\mathrm{ADH}$ reaction to meet the experimental $\mathrm{pH}$ of reaction solution and the optimization of other parameters enhanced its resistance to variations in data range and $\mathrm{ADH}$ activity. After optimization, iterative fitting to search for the intersecting point of two functions to estimate $A_{\mathrm{mk}}$ exhibited quick convergence. Therefore, the establishment of the correlation function between putative maximal product 
absorbance and desired steady-state concentration of acetaldehyde makes it feasible for iterative prediction of $A_{\mathrm{mk}}$ by fitting the integrated rate equation to $\mathrm{ADH}$ reaction curve.

By iterative fitting to predict $A_{\mathrm{mk}}$, this kinetic ADH method for serum ethanol assay exhibited resistance to common errors along with much higher efficiency than the equilibrium method. Usually a classical kinetic method exhibits higher precision for intra-run assays, but it is inevitably sensitive to the variation of enzyme activity and there will be $50 \%$ deviation when ADH activity is reduced by $50 \% .^{2}$ However, the deviation in $A_{\mathrm{mk}}$ predicted by this kinetic method was within $3 \%$, comparable to the overall variation coefficient of this kinetic ADH method, when there was $50 \%$ reduction in $\mathrm{ADH}$ activity. This property supported its stronger resistance to the variation of enzyme activity than that of the classical kinetic method. There was linear response of predicted $A_{\mathrm{mk}}$ to ethanol concentration in reaction solution with slope consistent to the preset absorptivity for NADH, which further supported the reliability of this kinetic $\mathrm{ADH}$ method and suggested that there is no absolute requirement for standards in routine practice with calibrated spectrophotometers. The upper limit by $A_{\mathrm{mk}}$ was much higher than the absorbance measurable by the spectrophotometer and the ratio of the upper limit to the lower limit of linear response for serum ethanol assay was $>40$-fold. For maximal $A_{\mathrm{mk}}$ predicted by this kinetic method with absorbance $<1.270$, the percentage of substrate consumption was $<70 \%$, but the resultant $A_{\mathrm{mk}}$ was still within the range of linear response. Therefore, this kinetic ADH method showed a linear response range wider than the equilibrium method. ${ }^{2}$ The optimized sample ratio in reaction solution will give the desired range of linear response, for example, $10 \mu \mathrm{l}$ protein-free sample in 1.20 $\mathrm{ml}$ mixture for analysis will give the linear range for 0.046 to $2.0 \mathrm{~g} / \mathrm{L}$ serum ethanol.

\section{Conclusions}

This kinetic strategy is applicable to irreversible enzyme reactions with product inhibition, ${ }^{7,10}$ and it is valid for $\mathrm{ADH}$ reaction with obvious reversibility and product inhibition. Moreover, it shows resistance to enzyme activity variation besides a wider range of linear response. Therefore, after optimizations of reaction conditions to simplify the integrated rate equation of enzyme reaction into the one that uses the predictor variable of reaction time, predicting detector signal after the completion of enzyme reaction by fitting to reaction curve with the integrated rate equation that takes product inhibition into account may be a universal kinetic method for enzymatic analysis with enhanced resistance to enzyme activity variation and expanded range of linear response.

\section{Acknowledgements}

This work was supported by the National Natural Sciences Foundation of China (No. 30200266).

\section{References}

1. E. Young and B. Ratter-Tadgell, Clin. Chem., 1987, 33, 2296.

2. A. Poklis and M. A. Mackell, Clin. Chem., 1982, 28, 2125.

3. F. Liao, K. C. Tian, X. Yang, Q. X. Zhou, Z. C. Zeng, and Y. P. Zuo, Anal. Bioanal. Chem., 2003, 375, 756.

4. F. Liao, Y. S. Zhao, L. N. Zhao, J. Tao, X. Y. Zhu, Y. M. Wang, and Y. P. Zuo, J. Med. Coll. PLA, 2005, 20, 338.

5. F. Liao, X. Y. Zhu, Y. M. Wang, and Y. P. Zuo, J. Biochem. Biophys. Methods, 2005, 62, 13.

6. F. Liao, Y. S. Zhao, L. N. Zhao, J. Tao, X. Y. Zhu, and L. Liu, J. Zhejiang Univ. Sci. B, 2006, 7, 497.

7. L. N. Zhao, J. Tao, Y. S. Zhao, and F. Liao, J. Xi'an Jiaotong Univ. Med. Sci., 2006, 27, 300.

8. Y. S. Zhao, L. N. Zhao, G. Q. Yang, J. Tao, Y. Q. Bu, and F. Liao, Biotechnol. Appl. Biochem., 2006, 45, 75.

9. A. J. Ganzhorn, D. W. Green, A. D. Hershey, R. M. Gould, and B. V. Plapp, J. Biol. Chem., 1987, 262, 3754.

10. V. L. Schramm, R. McCluskey, F. A. Emig, and G. Litwack, J. Biol. Chem., 1984, 259, 714.

\section{Appendix}

The integration of the rate equation for $A D H$ reaction

The reaction catalyzed by alcohol dehydrogenase in the presence of semicarbazide was:

Alcohol $+\mathrm{NAD}^{+} \underset{V 2}{\stackrel{V 1}{\rightleftharpoons}}$ Acetaldehyde $+\mathrm{NADH}+\mathrm{H}^{+}$

Acetaldehyde + Semicarbazide $\rightleftharpoons$ Condensed product

Symbols and abbreviations were defined as the following.

$A$, instantaneous absorbance; $A_{\mathrm{m}}$, maximal NADH absorbance after completion of ADH reaction; $B$, instantaneous ethanol concentration; $C$, NAD ${ }^{+}$concentration at 3.0 mmol/L; $e$, absorptivity of $\mathrm{NADH} ; \mathrm{H}^{+}$, hydrogen ion concentration; $K_{\mathrm{a}}, K_{\mathrm{b}}, K_{\mathrm{p}}$ and $K_{\mathrm{q}}$, Michaelis-Menten constants for NAD ${ }^{+}$, ethanol, acetaldehyde and $\mathrm{NADH}$, respectively; $K_{\mathrm{ia}}, K_{\mathrm{ib}}, K_{\mathrm{ip}}$ and $K_{\mathrm{iq}}$, inhibition constants for $\mathrm{NAD}^{+}$, ethanol, acetaldehyde and NADH, respectively; $P$, instantaneous acetaldehyde concentration; $Q$, instantaneous NADH concentration; $Q_{\mathrm{m}}$, maximal NADH concentration; $V 1$, forward reaction rate constant; $V 2$, reversal reaction rate constant.

The rate equation for $\mathrm{ADH}$ reaction was exactly the same as that reported by Ganzhorn et al., ${ }^{9}$

$$
V=\frac{V 1 \times C \times B-\frac{V 2 \times K_{\text {ia }} \times K_{\mathrm{b}}}{K_{\mathrm{p}} \times K_{\text {iq }}} \times P \times Q}{K_{\text {ia }} \times K_{\mathrm{b}}+K_{\mathrm{b}} \times C+K_{\mathrm{a}} \times B+C \times B+\frac{K_{\mathrm{q}} \times K_{\mathrm{ia}} \times K_{\mathrm{b}} \times P}{K_{\mathrm{p}} \times K_{\text {iq }}}+\frac{K_{\mathrm{i}} \times K_{\mathrm{b}} \times Q}{K_{\text {iq }}}+\frac{K_{\mathrm{b}} \times K_{\mathrm{q}} \times C \times P}{K_{\mathrm{p}} \times K_{\text {iq }}}+\frac{K_{\mathrm{q}} \times K_{\mathrm{ia}} \times K_{\mathrm{b}} \times B \times P}{K_{\mathrm{ib}} \times K_{\mathrm{p}} \times K_{\text {iq }}}+\frac{K_{\mathrm{ia}} \times K_{\mathrm{b}}}{K_{\mathrm{p}} \times K_{\text {iq }}} \times P \times Q+\frac{C \times B \times P}{K_{\text {ip }}}}
$$

Assigning $C=3.0 \mathrm{mmol} / \mathrm{L}, K_{\mathrm{eqh}}=\frac{V 1 \times K_{\mathrm{p}} \times K_{\mathrm{iq}} \times \mathrm{H}^{+}}{V 2 \times K_{\mathrm{b}} \times K_{\mathrm{ia}}}$ and $K_{\mathrm{eq}}=\frac{K_{\mathrm{eqh}}}{\mathrm{H}^{+}}$(adjusted to pH 8.8), respectively, and dividing both sides in Eq. (1) by $V 1$ gave Eq. (2). 


$$
\frac{V}{V 1}=\frac{3 \times B-\frac{P \times Q}{K_{\text {eq }}}}{K_{\text {ia }} \times K_{\mathrm{b}}+K_{\mathrm{b}} \times 3+\left(K_{\mathrm{a}}+3\right) \times B+\left(\frac{K_{\mathrm{q}}}{K_{\mathrm{eq}}}+\frac{3 \times K_{\mathrm{q}}}{K_{\mathrm{ia}} \times K_{\mathrm{eq}}}\right) \times P+\left(\frac{K_{\mathrm{p}}}{K_{\mathrm{eq}}}+\frac{P}{K_{\mathrm{eq}}}\right) \times Q+\left(\frac{3}{K_{\mathrm{ip}}}+\frac{K_{\mathrm{q}}}{K_{\mathrm{ib}} \times K_{\text {eq }}}\right) \times B \times P}
$$

Based on $B=Q_{\mathrm{m}}-Q$, there was Eq. (3).

$$
\frac{V}{V 1}=\frac{3 \times Q_{\mathrm{m}}-\left(3+\frac{P}{K_{\mathrm{eq}}}\right) \times Q}{\left[K_{\mathrm{ia}} \times K_{\mathrm{b}}+K_{\mathrm{b}} \times 3+\left(K_{\mathrm{a}}+3+\frac{3 \times P}{K_{\mathrm{eq}}}+\frac{K_{\mathrm{q}} \times P}{K_{\mathrm{ib}} \times K_{\mathrm{eq}}}\right) \times Q_{\mathrm{m}}+\left(\frac{K_{\mathrm{q}}}{K_{\mathrm{eq}}}+\frac{3 \times K_{\mathrm{q}}}{K_{\mathrm{ia}} \times K_{\mathrm{eq}}}\right) \times P\right]+\left[\frac{K_{\mathrm{p}}}{K_{\mathrm{eq}}}-\left(K_{\mathrm{a}}+3\right)-\left(\frac{K_{\mathrm{q}}}{K_{\mathrm{ib}} \times K_{\mathrm{eq}}}+\frac{3}{K_{\mathrm{ip}}}-\frac{1}{K_{\mathrm{eq}}}\right) \times P\right] \times Q}
$$

Based on $Q=\frac{A}{\varepsilon}$ and $Q_{\mathrm{m}}=\frac{A_{\mathrm{m}}}{\varepsilon}$, respectively, there was Eq. (4).

$$
\frac{V}{V 1}=\frac{3 \times A_{\mathrm{m}}-\left(3+\frac{P}{K_{\mathrm{eq}}}\right) \times A}{\left[\left(K_{\mathrm{ia}} \times K_{\mathrm{b}}+K_{\mathrm{b}} \times 3\right) \times \varepsilon+\left(K_{\mathrm{a}}+3+\frac{3 \times P}{K_{\mathrm{eq}}}+\frac{K_{\mathrm{q}} \times P}{K_{\mathrm{ib}} \times K_{\mathrm{eq}}}\right) \times A_{\mathrm{m}}+\left(\frac{K_{\mathrm{q}}}{K_{\mathrm{eq}}}+\frac{3 \times K_{\mathrm{q}}}{K_{\mathrm{ia}} \times K_{\mathrm{eq}}}\right) \times P \times \varepsilon\right]+\left[\frac{K_{\mathrm{p}}}{K_{\mathrm{eq}}}-\left(K_{\mathrm{a}}+3\right)-\left(\frac{K_{\mathrm{q}}}{K_{\mathrm{ib}} \times K_{\mathrm{eq}}}+\frac{3}{K_{\mathrm{ip}}}-\frac{1}{K_{\mathrm{eq}}}\right) \times P\right] \times A}
$$

We can define these terms

$$
\begin{aligned}
& M_{1}=\left(K_{\text {ia }} \times K_{\mathrm{b}}+K_{\mathrm{b}} \times 3\right) \times \varepsilon+\left(K_{\mathrm{a}}+3+\frac{3 \times P}{K_{\text {iq }}}+\frac{K_{\mathrm{q}} \times P}{K_{\mathrm{ib}} \times K_{\text {eq }}}\right) \times A_{\mathrm{m}}+\left(\frac{K_{\mathrm{q}}}{K_{\text {eq }}}+\frac{3 \times K_{\mathrm{q}}}{K_{\mathrm{ia}} \times K_{\text {eq }}}\right) \times \varepsilon \times P \\
& M_{2}=\frac{K_{\mathrm{p}}}{K_{\text {eq }}}-\left(K_{\mathrm{a}}+3\right)-\frac{K_{\mathrm{q}} \times P}{K_{\mathrm{ib}} \times K_{\text {eq }}}+\frac{3 \times P}{K_{\text {ip }}}-\frac{P}{K_{\text {eq }}} \\
& M_{3}=3 \times A_{\mathrm{m}} \quad M_{4}=3+\frac{P}{K_{\text {eq }}}
\end{aligned}
$$

Substitution of these terms into Eq. (4) gave Eq. (5).

$$
\frac{V}{V 1}=\frac{M_{3}-M_{4} \times A}{M_{1}+M_{2} \times A}
$$

Based on $V=\frac{\mathrm{d} Q}{\mathrm{~d} t}=\frac{\mathrm{d} A}{\varepsilon \times \mathrm{d} t}$, there was Eq. (6).

$$
\frac{\mathrm{d} A}{\varepsilon \times V 1}=\frac{M_{3}-M_{4} \times A}{M_{1}+M_{2} \times A} \times \mathrm{d} t
$$

The rearrangement of Eq. (6) gave Eq. (7).

$$
\frac{M_{1}+M_{2} \times A}{M_{3}-M_{4} \times A} \times \mathrm{d} A=V 1 \times \varepsilon \times \mathrm{d} t
$$

Equation (7) can be rearranged as the following to finally give Eq. (10)

$$
\begin{aligned}
& \frac{M_{1} \times M_{4}+M_{2} \times M_{4} \times A}{M_{3} \times M_{2}-M_{4} \times M_{2} \times A} \times \mathrm{d} A=\frac{M_{4}}{M_{2}} \times V 1 \times \varepsilon \times \mathrm{d} t \\
& \frac{\left(M_{1} \times M_{4}+M_{2} \times M_{3}\right) \times \mathrm{d} A}{M_{2} \times M_{3}-M_{2} \times M_{4} \times A}-\mathrm{d} A=\frac{M_{4}}{M_{2}} \times V 1 \times \varepsilon \mathrm{d} t \\
& \frac{M\left(M_{1} \times M_{4}+M_{2} \times M_{3}\right) \times \mathrm{d} A}{\frac{M_{2} \times M_{3}}{M_{2} \times M_{4}}}-A-M_{2} \times M_{4} \times \mathrm{d} A=M_{4}{ }^{2} \times V 1 \times \varepsilon \times \mathrm{d} t
\end{aligned}
$$

Taking $M_{5}=M_{1} \times M_{4}+M_{2} \times M_{3}$, presetting the steady-state concentration of residual acetaldehyde $(P)$ as a constant, the integration of Eq. (10) gave Eq. (12) with the predictor variable of reaction time.

$$
\begin{aligned}
& -M_{5} \times \ln \left(\frac{M_{3}}{M_{4}}-A\right)-M_{2} \times M_{4} \times A=a+M_{4}^{2} \times V 1 \times \varepsilon \times t \\
& -M_{5} \times \ln \left(\frac{M_{3}}{M_{4}}-A\right)-M_{2} \times M_{4} \times A=a+b \times t
\end{aligned}
$$

The intercept $a$ in Eq. (12) accounted for the lag time of steady-state reaction and product absorbance at the first datum for analysis. Equation (12) was fit to ADH reaction curve after data conversion according to the left part in Eq. (12) by presetting steady-state acetaldehyde concentration as a constant while $A_{\mathrm{m}}$ as a nonlinear parameter, and $A_{\mathrm{m}}$ for the best fitting based on $F$ value was the desired parameter. 